\section{BEYOND COMBINATION ANTI-HYPERTENSIVE} MEDICINES

Dear Editor,

In the October-December 2002 issue of JNMA, the editorial on "need of combination anti-hypertensive medicines in the market" has emphasized the value of such combination drugs in the market. ${ }^{1}$

The prevalence of high blood pressure is rapidly increasing in our community. Similarly the adverse vascular events of hypertension such as myocardial infarction, stroke, and peripheral vascular disease are not only quite frequently seen in our hospital wards but are also responsible for significant proportion of untimely deaths.

This burden of high blood pressure is even more compounded by the high prevalence of other cardiovascular risk factors like smoking, obesity, sedentary life style, and ever-increasing diabetes mellitus in the rapidly urbanizing population like ours. Undoubtedly this has imposed an enormous responsibility on the shoulder of a physician in detection, management, and prevention of all these risk factors.

The editorial has raised the very valid issue of combined antihypertensive drug treatment because most patients with hypertension will require 2 or more anti-hypertensive medications to achieve their blood pressure goals. It has been recommended that when the blood pressure is more than 20 / $10 \mathrm{~mm} \mathrm{Hg}$ above the recommended goal, consideration should be given to initiate therapy with 2 drugs either as separate prescriptions or in fixed-dose combinations. ${ }^{2}$ The united kingdom prospective diabetes study (UKPDS) ${ }^{3}$ has shown that increasing numbers of blood pressure lowering agents were required to obtain the tight blood pressure target of $<150 /<85$ $\mathrm{mm} \mathrm{Hg}$ in type 2 diabetic patients. Almost $30 \%$ of patients (27\% in the captopril group and $31 \%$ in the atenolol group) were taking three or more agents to control their blood pressure in that particular study.

The use of fixed-dose combination anti-hypertensive formulation has many advantages. Since these drugs have to be taken for long time and most of the hypertensive patients are often asymptomatic, people frequently do not like to use many drugs because of inconvenience. The fewer tablets the patients have to take, the more reliably will they use them, especially the elderly who as a group receive more drugs because they have multiple illnesses. Apart from this, reductions in blood pressure with combination drugs is additive and the adverse effects are said to be less than additive. It was found that using three blood pressure lowering drugs in low dose (half standard dose) combinations would reduce stroke by $63 \%$ and ischaemic heart disease events by $46 \%$ in the age group 60-69 years. ${ }^{4}$

Thiazide-type diuretics have been the basis of antihypertensive therapy in most outcome trials. This group of drug has been recommended in the treatment of most patients with uncomplicated hypertension, either alone or combined with drugs from other classes. ${ }^{2}$

Unfortunately efficacious and affordable thiazides like bendrofluazide and hydrochlorthiazide are not available in our market. Similarly fixed- dose combinations of diuretics with angiotensin converting enzyme inhibitors and angiotensin receptor blockers are also not available at present.

Now experts are even recommending Polypill ${ }^{5}$ (combination formulation containing six different agents: a statin, three blood pressure lowering drugs at half standard dose, folic acid, and aspirin). It is high time that we should at least try our best to optimize anti-hypertensive therapy with proper and rational use of combination drug therapy to achieve blood pressure goals. It is the responsibility of all involved authorities to coordinate and help from their level to make such products available in the market so as to help physicians and people at large.

\section{Dr. Buddhi P. Paudyal}

Butwal

\section{REFERENCES}

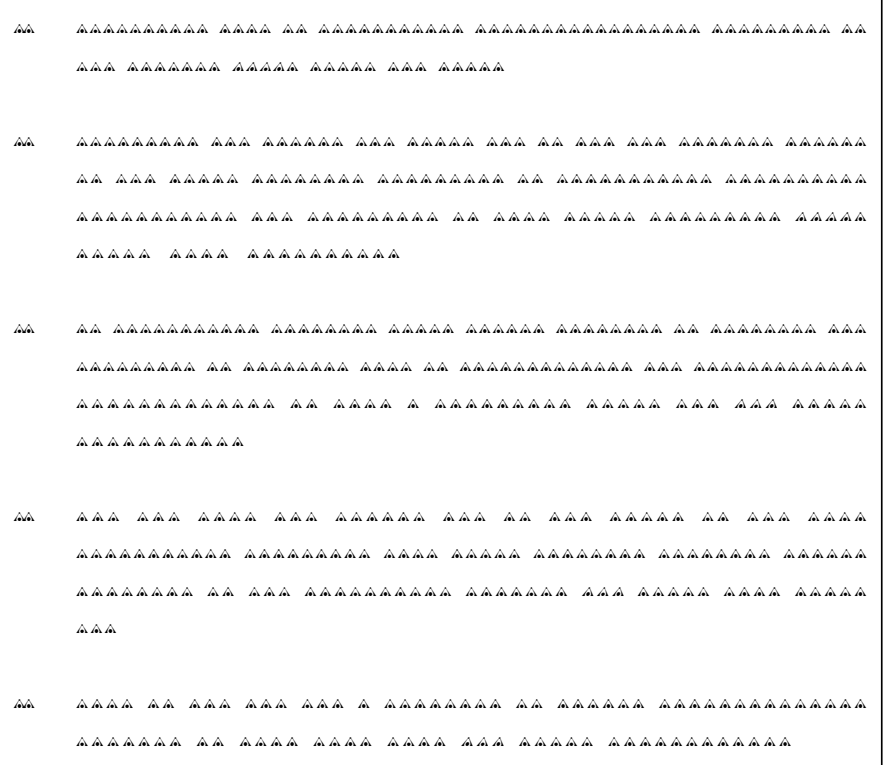

